\title{
Case Report of Hereditary Coproporphyria Accompanied by Nystagmus and Vestibular Dysfunction
}

\author{
Sadie M. Henry ${ }^{\text {a, c }}$, Mark M. Stanfield ${ }^{\text {b }}$
}

\begin{abstract}
Porphyria is a collection of disorders resulting from a breakdown in heme synthesis. The most common form is acute intermittent porphyria (AIP), and the other disorders are less common and therefore more difficult to diagnose. Our case study focuses on a 39-year-old male with a combination of gastrointestinal symptoms as well as neurocutaneous manifestations. Failing to recognize this disorder in the primary care setting can lead to additional, sometimes repetitive, clinical investigation and negative outcome for patients. The authors believe strongly in the teamwork model for today's medicine. Close communication between specialty and primary care, as well as a broader differential, could have helped achieve an earlier diagnosis and treatment for the patient.
\end{abstract}

Keywords: Hereditary coproporphyria; Acute intermittent porphyria; Porphyria; Nystagmus; Vestibular dysfunction; Photosensitivity

\section{Introduction}

Acute intermittent porphyria (AIP) occurs in approximately 1 in 20,000 patients annually, which is the highest prevalence of the porphyrias. Porphyria is a collection of disorders resulting from a breakdown in heme synthesis. The most common form is acute intermittent porphyria (AIP), and the other disorders are less common and therefore more difficult to diagnose. AIP occurs in approximately 1 in 20,000 patients annually. Clinically, porphyria is classified as acute, with associated neurovisceral symptoms as in $\delta$-aminolevulinic acid dehydratase porphyria (ADP) and AIP, or cutaneous, by its effects with sun-exposed skin. AIP can have cutaneous pathology late in the disease. The cutaneous category is further broken down to either chronic blistering, as in congeni-

Manuscript submitted September 13, 2018, accepted September 20, 2018

${ }^{a}$ Military Readiness Clinic, Naval Health Clinic Patuxent River, 47149 Buse Rd, Patuxent River, MD 20670, USA

bNaval Air Station Patuxent River, Patuxent River, MD, USA

${ }^{\mathrm{c} C o r r e s p o n d i n g ~ A u t h o r: ~ S a d i e ~ M . ~ H e n r y, ~ M i l i t a r y ~ R e a d i n e s s ~ C l i n i c, ~ N a v a l ~}$ Health Clinic Patuxent River, 47149 Buse Rd, Patuxent River, MD 20670, USA. Email: sadie.m.henry.mil@mail.mil

doi: https://doi.org/10.14740/jmc3158w tal erythropoietic porphyria (CEP), porphyria cutanea tarda (PCT) and hepatoerythropoietic porphyria (HEP), or acute/ non-blistering, which includes erythropoietic protoporphyria (EPP) and X-linked protoporphyria (XLP). Further still, hereditary coproporphyria (HCP) and variegate porphyria (VP) have both neurovisceral (i.e. abdominal pain, psychological and neurological disturbance) and cutaneous presentations [1].

\section{Case Report}

The 39-year-old white male patient in this report presented to a US Navy primary care physician with abdominal pain, neuropathy and psychological manifestations. His medical and social history was unremarkable, except for the fact that symptoms began approximately 9 years prior. Intermittently, he suffered from diarrhea up to five times per day, and it had become increasingly bothersome, with bloating and severe abdominal cramps that often resolved with each episode. Early in his medical history, he was given a diagnosis of irritable bowel syndrome and was treated symptomatically. Specialties that consulted this case included hematology, genetics, neurology and dermatology.

His symptoms complicated when he presented with dizziness, nystagmus and tinnitus. He had a normal MRI of the brain and a normal audiogram, but was noted to have intermittent oscillopsia, new-onset headaches, and was diagnosed with bilateral vestibular dysfunction.

There was a marked photosensitivity and with UV exposure, blistering occurred on the patient's scalp, arms and chest. This patient typically presented with tingling on his scalp after yard work or sun exposure, which progressed to pustules and blisters shortly thereafter. This was thought to have been polymorphous light eruptions (PMLE), but it is highly unusual for eruptions to develop after each instance of UV exposure.

Neurologically, there is no history of seizure disorder or hallucinations. He had received a diagnosis of attention deficit hyperactivity disorder (ADHD) several years prior and experienced steadily increasing difficulty with mental focus in recent years. He also suffers from frequent insomnia. Psychologically, there is no history of depression or other mood disorder. The patient has become more forgetful than usual. A neurological evaluation yielded a glottic, valsalva-induced dizziness and vertigo. Nystagmus was a key clinical discovery. Porphyria was suspected after many years of consultation and 
Table 1. Laboratory Values Symptomatic Versus Asymptomatic

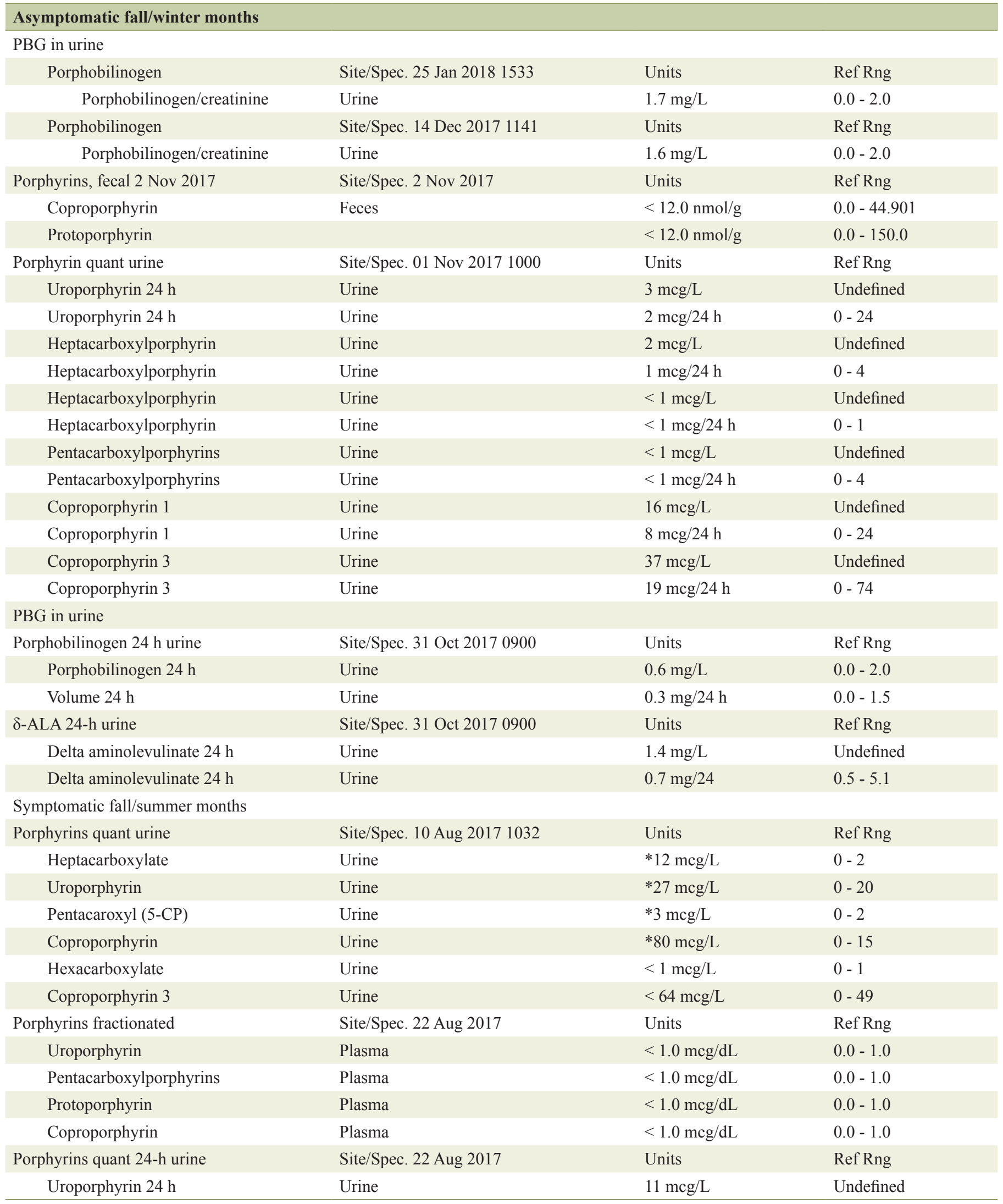


Table 1. Laboratory Values Symptomatic Versus Asymptomatic - (continued)

\begin{tabular}{llll}
\hline Asymptomatic fall/winter months & & & \\
\hline Uroporphyrin $24 \mathrm{~h}$ & Urine & $7 \mathrm{mcg} / 24 \mathrm{~h}$ & $0-24$ \\
Heptacarboxylporphyrin & Urine & $5 \mathrm{mcg} / \mathrm{L}$ & Undefined \\
Heptacarboxylporphyrin & Urine & $3 \mathrm{mcg} / 24 \mathrm{~h}$ & $0-4$ \\
Heptacarboxylporphyrin & Urine & $1 \mathrm{mcg} / \mathrm{L}$ & Undefined \\
Heptacarboxylporphyrin & Urine & $1 \mathrm{mcg} / 24 \mathrm{~h}$ & $0-1$ \\
Pentacarboxylporphyrins & Urine & $1 \mathrm{mcg} / \mathrm{L}$ & Undefined \\
Pentacarboxylporphyrins & Urine & $1 \mathrm{mcg} / 24 \mathrm{~h}$ & $0-4$ \\
Coproporphyrin 1 & Urine & $53 \mathrm{mcg} / \mathrm{L}$ & Undefined \\
Coproporphyrin 1 & Urine & $* 32 \mathrm{mcg} / 24 \mathrm{~h}$ & $0-24$ \\
Coproporphyrin 3 & Urine & $46 \mathrm{mcg} / \mathrm{L}$ & Undefined \\
Coproporphyrin 3 & Urine & $28 \mathrm{mcg} / 24 \mathrm{~h}$ & $0-24$ \\
\hline
\end{tabular}

treatment-related ailments and with no positive outcome.

\section{Clinical diagnosis}

Because of abdominal pain, diarrhea, tachycardia, mild hypertension and psychological problems, an initial diagnosis of AIP was considered just over a year ago; however, AIP does not address cutaneous effects. In the preceding 2 years, red blood cell (RBC) assay for porphobilinogen deaminase (PBGD) level and $\delta$-aminolevulinic acid (ALA) was initially negative, most likely because he was tested when asymptomatic (Table 1). Other signs, such as the extensive blistering of the skin following UV exposure, nystagmus and vestibular dysfunction exhibited by this patient, were not consistent with AIP. Clinical presentation of neurocutaneous signs and symptoms led the authors to a suspicion that either dual porphyria or HCP was the complete diagnosis.

Cutaneous porphyrias often involve edema, redness and blistering of the skin [2], especially with UV exposure. The neurocutaneous porphyrias [3], VP and HCP, were candidates for additional diagnosis because they captured the remaining elements of the patient's ailment, namely, vestibular dysfunction. Such autonomic neuropathies are common with neurological forms of porphyria $[2,4,5]$.

\section{Blood testing}

Tests of the patient's whole blood, which sought uroporphyrin, coproporphyrin and protoporphyrin, were inconclusive. When referred to specialty care, this patient's blood was tested when asymptomatic. The timeliness of blood and plasma testing for porphyria (i.e. when symptoms are present) is important to emphasize [6]. Blood tests for ALA and PBG and its precursors will be repeated when the patient is symptomatic.

\section{Stool/urine tests}

A test for fecal protoporphyrins and coproporphyrins was com- pleted with no significant result, but this was most likely a result of testing an asymptomatic patient. Following diagnostic criteria [5], in one urine test, heptacarboxylate, pentacarboxyl, coproporphyrin I/III and uroporphyrin were all elevated from normal values. ALA and PBG have been tested with no appreciable increase during either acute or latent phases.

It is essential to analyze urine for porphyrin, its precursors, ALA and PBG [6, 7]. Values can be elevated between and during acute attacks, and up to $10 \%$ of people can have normal levels regardless [8]. Of note, the patient's urine porphyrins were elevated in the summer months, during his photosensitive outbreaks, but were negative later in the cooler months of the year.

\section{Biopsy}

A vertex and posterior scalp punch biopsy that was taken from a photosensitive lesion following ultraviolet exposure showed marked superficial and deep inflammation with subdermal blistering. These findings are consistent with neurocutaneous porphyria, especially considering the photoactive nature of porphyrin in the skin $[9,10]$.

\section{Genetic screening}

Porphyria research in the 1980s and 1990s largely pointed to enzymatic analysis for diagnostic confirmation of porphyria $[2,5,11]$. Recent literature suggests that porphyria diagnoses in a clinical setting should be confirmed via genetic study [3, $4,12,13]$. A gene panel was completed via array comparative genomic hybridization $(\mathrm{aCGH})$ with specific detection for ALAS2, CPOX, FECH, HMBS, PPOX and UROD, the results of which were negative for deletion and duplication.

\section{Family/social history}

The patient has a significant travel history as part of a long military career. There is no significant family history of dermatolog- 
ical conditions or metabolic diseases. He is married, has never smoked, does not abuse alcohol and has no history of illicit drug use. The patient is of approximately $60 \%$ British ancestry, with no other family members affected by any form of porphyria.

\section{Treatment and prognosis}

Currently, the patient has not been diagnosed with any one unifying ailment. Instead he is being treated separately for ADHD, irritable bowel syndrome (IBS) and vertigo, with little improvement in symptoms. His current medications are adderall, maxzide, imitrex and trazodone. He continues to have numbness in his mouth, visual disturbances/vertigo, headaches/migraines, vesicular lesions of the scalp in the summer months, gastrointestinal distress and increasing memory loss. He was a highly productive military service member who can no longer work or drive a vehicle. This degradation occurred in a matter of 2 years' time.

\section{Conclusions}

The purpose of this case report is to make clinicians aware of the possibility of a rare presentation of porphyria. Early identification means early treatment, with an abrupt end to disorder progression. The goal of this report is to highlight a recent clinical finding of a unique disorder with an initially challenging cutaneous and vestibular finding.

It is necessary that tests for porphyria are sought while a patient is symptomatic or under acute attack. This patient's case could have been managed more effectively if other possible diagnoses had been more carefully evaluated. It is important to keep a wide differential when cases present in an unusual manner.

The authors wish to emphasize the increasing importance of a team approach and multiple disciplinary focus in modern medicine. The initial diagnosis and treatment of porphyria can be primary care/general practice-centric, and inter-departmental communication with all specialties involved is essential to the best patient outcome, as others have asserted $[14,15]$.

\section{Acknowledgments}

We thank Dr. Robert Desnick of the Icahn School of Medicine at Mount Sinai, New York and Dr. Jorge Frank of the University Medical Center Göttingen.

\section{Author Contributions}

The authors are primary care providers and/or researchers of the subject and maintain access to medical record/data/material.

\section{Ethics Approval and Consent}

Ethics approval and consent to participate and patient consent for publication have been acquired.

\section{Previous Presentations}

None.

\section{Financial Support}

None.

\section{Disclosure}

The views expressed are solely those of the authors and do not reflect the official policy or position of the Department of Defense.

\section{References}

1. McColl KE, Moore R. The porphyrias: an example of pharmacogenetic disease. Scott Med J. 1981;26(1):32-40.

2. Chan KM, Ladenson JH, Vaidya HC, Kanan R. Washington University case conference. Dual porphyria - an underdiagnosed entity? Clin Chem. 1987;33(7):11901193.

3. Poblete-Gutierrez P, Badeloe S, Wiederholt T, Merk HF, Frank J. Dual porphyrias revisited. Exp Dermatol. 2006;15(9):685-691.

4. Anyaegbu E, Goodman M, Ahn SY, Thangarajh M, Wong M, Shinawi M. Acute intermittent porphyria: a diagnostic challenge. J Child Neurol. 2012;27(7):917-921.

5. Tefferi A, Colgan JP, Solberg LA, Jr. Acute porphyrias: diagnosis and management. Mayo Clin Proc. 1994;69(10):991995.

6. Woolf J, Marsden JT, Degg T, Whatley S, Reed P, Brazil $\mathrm{N}$, Stewart MF, et al. Best practice guidelines on firstline laboratory testing for porphyria. Ann Clin Biochem. 2017;54(2):188-198.

7. Warner TT, Hammans SR. Practical Guide to Neurogenetics. Philadelphia: Saunders/Elsevier. 2009.

8. Anderson KE, Sassa S, Bishop DF, Desnick RJ. Disorders of heme biosynthesis: $x$-Linked sideroblastic anemia and the porphyrias. In Valle D, Beaudet AL, Vogelstein B, et al, Editors. The Online Metabolic and Molecular Bases of Inherited Disease. New York: McGraw-Hill, 2014.

9. Afonso SG, Enriquez de Salamanca R, Batlle AM. The photodynamic and non-photodynamic actions of porphyrins. Braz J Med Biol Res. 1999;32(3):255-266.

10. Moore MR, McColl KEL, Rimington C, Goldberg A. Disorders of Porphyrin Metabolism. New York: Plenum Medical Book Company; 1987.

11. McColl KE, Thompson GG, Moore MR, Goldberg A, Church SE, Qadiri MR, Youngs GR. Chester porphyria: biochemical studies of a new form of acute porphyria. Lancet. 1985;2(8459):796-799. 
12. Kuo HC, Huang CC, Chu CC, Lee MJ, Chuang WL, Wu $\mathrm{CL}, \mathrm{Wu} \mathrm{T}$, et al. Neurological complications of acute intermittent porphyria. Eur Neurol. 2011;66(5):247-252.

13. Poblete-Gutierrez P, Wiederholt T, Martinez-Mir A, Merk HF, Connor JM, Christiano AM, Frank J. Demystification of Chester porphyria: a nonsense mutation in the Porphobilinogen Deaminase gene. Physiol Res. 2006;55(Suppl 2):S137-144.
14. Katugampola RP, Badminton MN, Finlay AY, Whatley S, Woolf J, Mason N, Deybach JC, et al. Congenital erythropoietic porphyria: a single-observer clinical study of 29 cases. Br J Dermatol. 2012;167(4):901-913.

15. Qadiri MR, Church SE, McColl KE, Moore MR, Youngs GR. Chester porphyria: a clinical study of a new form of acute porphyria. Br Med J (Clin Res Ed). 1986;292(6518):455-459. 